\title{
Comparison of the renal safety between carbon dioxide absorbent products under sevoflurane anesthesia: a pilot study
}

\author{
Hyung-Chul Lee ${ }^{1}$, Donguk Kim², Wonsik Ahn $^{1,3}$, Jiyeon $\mathrm{Sim}^{4}$, and Yehoon Chung ${ }^{1}$ \\ ${ }^{1}$ Department of Anesthesiology and Pain Medicine, Seoul National University Hospital, ${ }^{2}$ Department of Statistics, Sungkyunkwan \\ University, ${ }^{3}$ Institute of Medical and Biological Engineering, Medical Research Center, Seoul National University, ${ }^{4}$ Department of \\ Anesthesiology and Pain Medicine, College of Medicine, University of Ulsan, Seoul, Korea
}

Background: The chemical reaction of carbon dioxide absorbent and sevoflurane is known to produce compound A. However, carbon dioxide absorbents are not controlled by the Food and Drug Administration, but are treated as industrial products in some nations. Moreover, carbon dioxide absorbents differ in their capacities to produce compound A, because their chemical compositions differ. In this study, we compared the renal safety between carbon dioxide absorbent products in patients under sevoflurane anesthesia.

Methods: Eighty patients with no preexisting renal disease undergoing elective gynecologic surgery were randomly assigned to receive sevoflurane or isoflurane anesthesia with one of four carbon dioxide absorbent products (Sodasorblime $^{\circledR}$, Sodalyme $^{\circledR}$, Sodasorb $^{\circledR}$, Spherasorb $^{\circledR}$ ) at the same fresh gas flow of $2 \mathrm{~L} / \mathrm{min}$. The renal safety was evaluated by changes of blood urea nitrogen (BUN), creatinine and urine N-acetyl-b-glucoseaminidase (NAG)creatinine ratio at 24 hours and 72 hours after surgery from preoperative level.

Results: There was no significant difference in the renal safety indicators between carbon dioxide absorbents during sevoflurane anesthesia $(\mathrm{P}>0.05)$. However, the BUN and urine NAG-creatinine ratios at 72 hours after surgery were higher in isoflurane anesthesia in some carbon dioxide absorbent groups ( $\mathrm{P}=0.03$ and 0.04 , respectively).

Conclusions: We could not find significant differences of renal safety indicators with carbon dioxide absorbents. Although the adverse effect of carbon dioxide absorbents on renal function was not proved, consideration should be given to their contol by the regulation on their efficacy and safety because carbon dioxide absorbents can produce compound A. (Korean J Anesthesiol 2012; 63: 11-17)

Key Words: Adverse effects, Anesthetics, Inhalation, Kidney, Sevoflurane.

\footnotetext{
Received: October 24, 2011. Revised: November 15, 2011. Accepted: November 23, 2011.

Corresponding author: Wonsik Ahn, M.D., Department of Anesthesiology and Pain Medicine, Seoul National University Hospital, 101, Daehang-no, Jongno-gu, Seoul 110-744, Korea. Tel: 82-2-2072-3087, Fax: 82-2-766-3087, E-mail: aws@snu.ac.kr The abstracts of this article were presented at the 86th conference of the Korean Society of Anesthesiologists, 6th November, 2009.

(c) This is an open-access article distributed under the terms of the Creative Commons Attribution Non-Commercial License (http:// creativecommons.org/licenses/by-nc/3.0/), which permits unrestricted non-commercial use, distribution, and reproduction in any medium, provided the original work is properly cited.
} 


\section{Introduction}

Inhalation anesthesia with sevoflurane has been widely used recently because of its fast emergence and fewer side effects. However, it is known that carbon dioxide absorbent in the circular breathing system can degrade sevoflurane to compound A (fluoromethyl-2, 2-difluoro-1-(trifluoromethyl) vinyl ether) which is nephrotoxic in animals [1]. Especially, during low flow anesthesia, which is increased nowadays by advances in anesthetic equipment, more compound A could be produced [2-4]. While compound A can cause renal tubular necrosis in animals, it has potential nephrotoxicity in humans when exposed over a certain level [5]. For this reason, in the United States, carbon dioxide absorbents are treated as a medical device by the Food and Drug Administration (FDA) (21CFR868.5300). However, in some contries, they are not classified as a medical device [6].

Nevertheless, the chemical composition of carbon dioxide absorbents can affect their capacities to produce compound A [7]. Thus, the carbon dioxide absorbent products made by various chemical compositions may differ in renal safety during sevoflurane anesthesia. In fact, according to our survey of the carbon dioxide absorbent products in the market, they differ from each other in chemical composition (Table 1). Until now, only a few studies have been conducted on animals or with the use of an artificial lung model [8-11]. Clinical studies about the renal safety of carbon dioxide absorbent products are scarce [12]. To the best of our knowledge, there is no study that compares the renal safety of carbon dioxide absorbent products using a renal injury marker during the perioperative period. Therefore, we conduct a clinical study of the perioperative renal safety of carbon dioxide absorbent products in patients undergoing sevoflurane anesthesia.

\section{Materials and Methods}

This study was approved by the Institutional Review Board of Seoul National University Hospital (H-0901-033-268) and all patients gave written informed consent. The subjects were 80 wemen, aged 20 to 80 years, scheduled for elective surgery of the uterus, ovary, or adnexa under general anesthesia with an expected duration of at least two hours. Patients were excluded if they were pregnant or breast-feeding, if they had an abnormality in the renal function test or if they had received anesthesia within one month.

Each subject was randomized into one of eight groups and underwent general anesthesia with one of four carbon dioxide absorbent products (Group A: Sodasorblime ${ }^{\circledR}$ [Dong-a healthcare Co., Ltd., Seoul, Korea], Group B: Sodalyme ${ }^{\circledR}$ [Cogsi Co., Ltd., Seoul, Korea], Group C: Sodasorb ${ }^{\circledR}$ [W. R. Grace \& Co., Columbia, Maryland, US], Group D: Spherasorb ${ }^{\circledR}$ [Intersurgical Ltd., Wokingham, Berkshire, UK]) and two anesthetic agents (sevoflurane or isoflurane as a control). Before induction of anesthesia, the used carbon dioxide absorbent was replaced with a new carbon dioxide absorbent based on the study group to which the patient was assigned. The Dräger Primus (Dräger Medical, Lübeck, Germany) anesthetic machine with a semicircular breathing system was used.

Anesthesia was induced with thiopental or propofol and fentanyl. After loss of consciousness, vecuronium or rocuronium was injected and the patient's trachea was intubated after paralysis. For maintenance of anesthesia, sevoflurane or isoflurane with the fresh gas flow of $2 \mathrm{~L} / \mathrm{min}$ was used according to the patient's group. The mechanical ventilator was set at volume control mode with a tidal volume of $10 \mathrm{ml} / \mathrm{kg}$, a respiration rate of $10 / \mathrm{min}$, and an inspiration/expiration ratio of $1: 2$. The fraction of inspired oxygen was $50 \%$ with medical air. During operation, the expiratory concentration of sevoflurane was maintained above 1 vol\%. If any drugs were used that had a renal side effect, they were documented. Intraoperative fluid administrations are guided by hemodynamic status, blood loss, and urine output. After the operation finished, sevoflurane was discontinued and the fresh gas flow was increased to $6 \mathrm{~L} / \mathrm{min}$ with $100 \%$ oxygen. Pyridostigmine and glycopyrrolate were used for reversal of residual muscle relaxation.

Intraoperative heart rates, blood pressures, peripheral oxygen saturation, body temperature and inspiratory and expiratory concentration of oxygen and anesthetic agent were recorded every five minutes. Blood and urine samples were obtained at preoperative, 24 and 72 hours after operation and blood urea nitrogen (BUN), serum creatinine and urine $\mathrm{N}$-acetyl-b-glucoseaminidase (NAG)-creatinine ratio were measured. The exposure of sevoflurane was compared using minimum alveolar concentration (MAC) multiplied by hours. A

Table 1. The Chemical Compositions of Carbon Dioxide Absorbents

\begin{tabular}{llrrr}
\hline \multicolumn{1}{c}{ Product name } & \multicolumn{1}{c}{ Manufacturer } & $\mathrm{Ca}(\mathrm{OH})_{2}$ & $\mathrm{NaOH}$ & $\mathrm{KOH}$ \\
\hline Sodasorblime $^{\circledR}$ (Group A) & Dong-a healthcare & $76.3 \%$ & $11.6 \%$ & $4.5 \%$ \\
Sodalyme $^{\circledR}$ (Group B) & Cogsi & $73-85 \%$ & $2-5 \%$ & $0.5-3 \%$ \\
Sodasorb $^{\circledR}$ (Group C) & W. R. Grace & $50-100 \%$ & $<4 \%$ & $12-19 \%$ \\
Spherasorb $^{\circledR}$ (Group D) & Intersurgical & $75-80 \%$ & $2.5 \%$ & $15-17 \%$ \\
\hline
\end{tabular}


MAC value of 2.05 vol\% was employed for sevoflurane [13].

For postoperative pain management, intravenous patient controlled analgesia (PCA) was used. Morphine $50 \mathrm{mg}$, ketorolac 90-150 $\mathrm{mg}$ and ramosetron $0.3 \mathrm{mg}$ mixed with $100 \mathrm{ml}$ of normal saline was infused at a rate of $1 \mathrm{ml} / \mathrm{h}$, plus a bolus of 1 $\mathrm{ml}$ with a lock out time of $15 \mathrm{~min}$. The total amount of ketorolac used for PCA was documented. If a patient was treated with additional nonsteroidal antiinflammatory drug (NSAID), the name and dose were recorded and compared between groups.

Statistical analysis was performed using repeated measures analysis of variance (ANOVA) for the changes of serum BUN, creatinine and urine NAG-creatinine ratio in each carbon dioxide absorbent product group. The difference of these markers between sevoflurane and isoflurane was also compared using t-test in each carbon dioxide absorbent product group. In the patients using sevoflurane, repeated measures analysis of variance was performed to find the difference between the carbon dioxide absorbent products with $(>0.5 \%)$ and without $\mathrm{KOH}$. A value of $\mathrm{P}<0.05$ was considered significant in all studies. Results are expressed as mean \pm SD.

\section{Results}

There were no cases of intra- or postoperative hemodynamic instability. Of the 80 subjects, three were excluded by withdrawal of agreement, three were excluded by anesthesia shorter than two hours, two were excluded by changes of schedule, one was excluded by pregnancy revealed at operation day, and one was excluded by malfunction of prepared isoflurane vaporizer. In the remaining 70 subjects, sex, age, height, weight, exposure to anesthetic agent, operation time, amount of crystalloid and colloid administration, blood loss, urine output, transfusion, type of surgery, and the incidence of laparoscopic procedure did not differ significantly between groups (Table 2). In addition, there was no inter-group difference in preoperative comorbidities (diabetes mellitus, hypertension, pulmonary tuberculosis, liver disease) and in the use of anti-hypertensive drugs and oral hypoglycemic agent. Intraoperative use of thiopental, propofol, vecuronium, rocuronium, and fentanyl, and postoperative dose of ketorolac used for patient controlled analgesia also did not show statistically significant differences. No subject used non-steroidal anti-inflammatory drugs for pain management in addition to PCA during the study period.

The preoperative BUN, serum creatinine, and urine NAGcreatinine ratio of all subjects were $11.4 \pm 3.2 \mathrm{mg} / \mathrm{dl}, 0.74 \pm 0.10$ $\mathrm{mg} / \mathrm{dl}$, and $5.4 \pm 3.4 \mathrm{IU} / \mathrm{g} \mathrm{Cr}$, respectively. These markers did not differ significantly between sevoflurane and isoflurane $(\mathrm{P}=$ $0.331,0.452$, and 0.756 , Table 3 ).

The repeated measures ANOVA revealed no significant difference in changes (preoperative, 24 and 72 hours after surgery) of BUN, creatinine, and urine NAG-creatinine ratios between the patients who had anesthesia with sevoflurane and

Table 2. Patients Characteristics in each Study Group

\begin{tabular}{|c|c|c|c|c|c|c|c|c|}
\hline \multirow{3}{*}{ Group } & \multicolumn{2}{|c|}{ A } & \multicolumn{2}{|c|}{ B } & \multicolumn{2}{|c|}{$\mathrm{C}$} & \multicolumn{2}{|c|}{$\mathrm{D}$} \\
\hline & Sevo.* & Iso. $^{\dagger}$ & Sevo. & Iso. & Sevo. & Iso. & Sevo. & Iso. \\
\hline & $\mathrm{n}=7$ & $\mathrm{n}=11$ & $\mathrm{n}=8$ & $\mathrm{n}=6$ & $\mathrm{n}=9$ & $\mathrm{n}=12$ & $\mathrm{n}=10$ & $\mathrm{n}=7$ \\
\hline Age (yr) & $40.7 \pm 6.7$ & $39.7 \pm 5.9$ & $39.1 \pm 5.6$ & $45.3 \pm 6.4$ & $38.7 \pm 6.3$ & $41.0 \pm 9.3$ & $45.4 \pm 13.9$ & $41.0 \pm 10.0$ \\
\hline Height $(\mathrm{cm})$ & $155.5 \pm 7.3$ & $159.7 \pm 5.0$ & $157.8 \pm 4.0$ & $159.6 \pm 7.0$ & $160.4 \pm 4.1$ & $158.2 \pm 5.9$ & $157.2 \pm 6.3$ & $162.8 \pm 7.4$ \\
\hline Weight (kg) & $58.8 \pm 8.7$ & $59.5 \pm 10.2$ & $57.2 \pm 14.0$ & $56.9 \pm 7.0$ & $57.4 \pm 6.6$ & $56.1 \pm 6.8$ & $55.6 \pm 10.6$ & $55.6 \pm 4.1$ \\
\hline $\mathrm{EBL}^{\dagger}(\mathrm{ml})$ & $357 \pm 505$ & $282 \pm 420$ & $219 \pm 153$ & $188 \pm 193$ & $225 \pm 131$ & $259 \pm 233$ & $193 \pm 301$ & $236 \pm 99$ \\
\hline Urine (ml) & $254 \pm 233$ & $218 \pm 220$ & $276 \pm 433$ & $182 \pm 181$ & $236 \pm 152$ & $236 \pm 281$ & $147 \pm 189$ & $484 \pm 337$ \\
\hline Crystalloid (ml) & $883 \pm 546$ & $948 \pm 338$ & $625 \pm 238$ & $1,258 \pm 674$ & $950 \pm 228$ & $1,058 \pm 608$ & $1,045 \pm 590$ & $1,017 \pm 330$ \\
\hline Colloid (ml) & $214 \pm 267$ & $100 \pm 300$ & $0 \pm 0$ & $67 \pm 163$ & $13 \pm 35$ & $142 \pm 223$ & $60 \pm 190$ & $83 \pm 204$ \\
\hline Exposure $\left(\mathrm{MAC}^{\S} \mathrm{h}\right)$ & $2.4 \pm 0.9$ & $2.5 \pm 0.8$ & $2.3 \pm 0.6$ & $2.6 \pm 1.1$ & $2.5 \pm 1.1$ & $2.1 \pm 0.9$ & $2.3 \pm 1.1$ & $2.2 \pm 0.5$ \\
\hline Operation time (h) & $2.5 \pm 0.8$ & $2.7 \pm 0.8$ & $2.6 \pm 0.5$ & $2.7 \pm 1.1$ & $2.7 \pm 1.1$ & $2.2 \pm 0.9$ & $2.5 \pm 1.1$ & $2.4 \pm 0.5$ \\
\hline Transfusion (n) & 1 & 0 & 0 & 0 & 0 & 0 & 0 & 0 \\
\hline \multicolumn{9}{|l|}{ Type of surgery } \\
\hline Uterus & 1 & 2 & 2 & 3 & 2 & 3 & 4 & 3 \\
\hline Ovary & 2 & 6 & 5 & 1 & 5 & 5 & 3 & 2 \\
\hline Both & 3 & 3 & 1 & 2 & 2 & 3 & 3 & 2 \\
\hline Others & 1 & 0 & 0 & 0 & 0 & 1 & 0 & 0 \\
\hline \multicolumn{9}{|l|}{ Laparoscopy } \\
\hline Yes & 3 & 3 & 2 & 3 & 4 & 1 & 6 & 5 \\
\hline No & 4 & 8 & 6 & 3 & 5 & 11 & 4 & 2 \\
\hline Ketorolac (mg) & 124 & 109 & 120 & 120 & 120 & 95 & 93 & 120 \\
\hline
\end{tabular}

There are no significant difference between parameters in each study group. ${ }^{*}$ Sevo.: sevoflurane, ${ }^{\dagger}$ Iso.: isoflurane, ${ }^{\dagger}$ EBL: estimated blood loss,

${ }^{\S}$ MAC: minimum alveolar concentration. 
Table 3. Preoperative Renal Safety Indicators of the Subjects with Respect to the Anesthetic Agent

\begin{tabular}{lcccc}
\hline & Sevoflurane & Isoflurane & Total & P value \\
\hline BUN (mg/dl) & $11.0 \pm 3.2$ & $11.8 \pm 3.2$ & $11.4 \pm 3.2$ & 0.3312 \\
Creatinine (mg/dl) & $0.73 \pm 0.10$ & $0.75 \pm 0.10$ & $0.74 \pm 0.10$ & 0.4524 \\
Urine NAG/Cr (IU/g Cr) & $5.3 \pm 3.6$ & $5.6 \pm 3.2$ & $5.4 \pm 3.4$ & 0.7560 \\
\hline
\end{tabular}
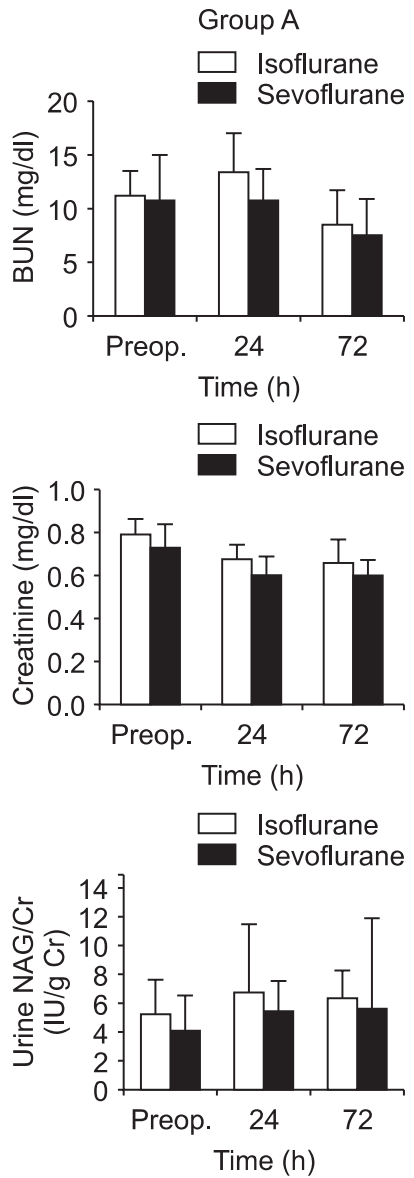
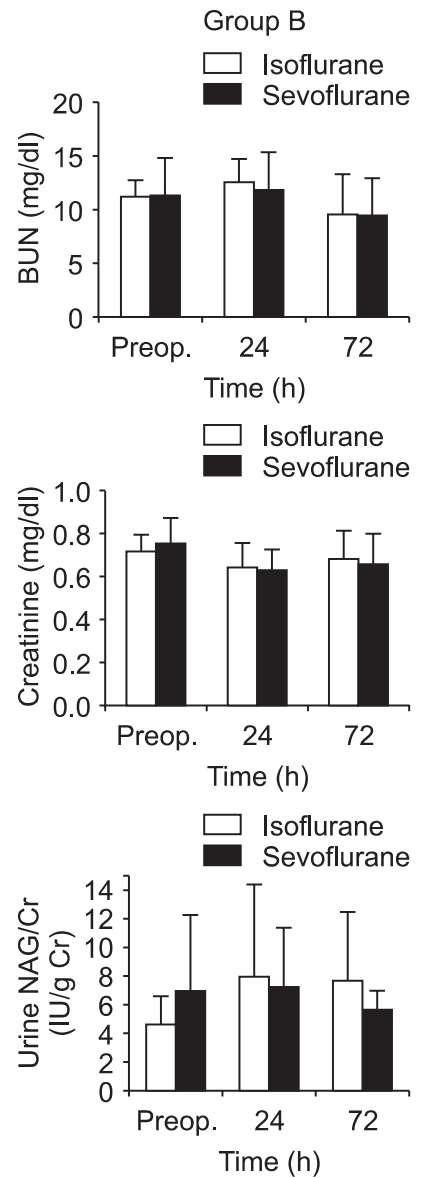
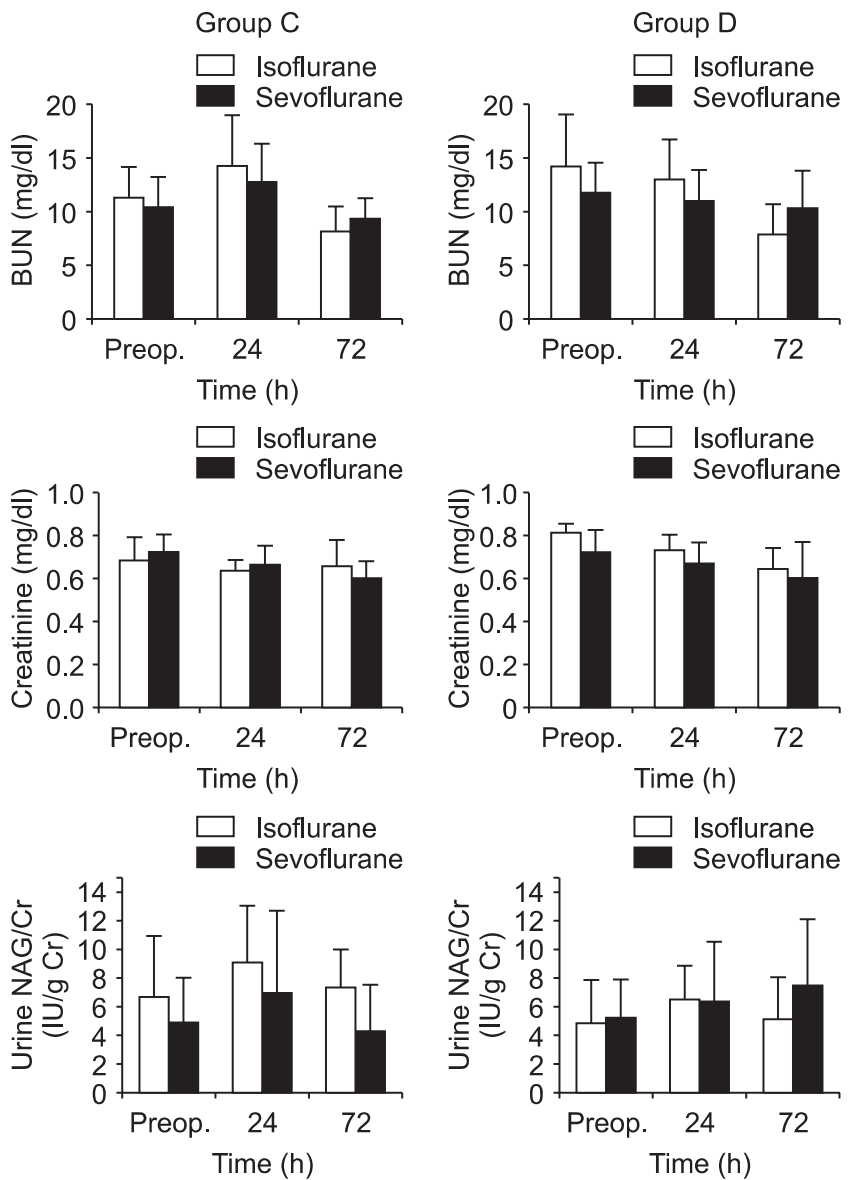

Fig. 1. The plots of serum BUN, creatinine and urine NAG-creatinine ratio in each group at preoperative, 24 hours and 72 hours after surgery. There were no significant differences between groups except for BUN, which was changed at 72 hours after surgery from the preoperative value in group $\mathrm{D}(\mathrm{P}=0.03)$. Preop.: Preoperative.

with isoflurane $(\mathrm{P}=0.446,0.073,0.442)$. With the same analysis, no difference was found between the sevoflurane and the isoflurane subgroups in each carbon dioxide absorbent product group (Fig. 1).

Compared with the preoperative value, renal markers at 24 hours after surgery also did not differ in all groups. The urine NAG-creatinine ratio at 72 hours after surgery was lower in the sevoflurane than in the isoflurane subgroup in the carbon dioxide absorbent group $\mathrm{C}(\mathrm{P}=0.0437$, Table 4$)$. Changes of serum BUN at 72 hours after surgery from the preoperative value were less in the patients with sevoflurane than isoflurane in group $\mathrm{D}(\mathrm{P}=0.03$, Table 5$)$.
Among the four carbon dioxide absorbents investigated in this study, two contained $\mathrm{KOH}$. However, in patients using sevoflurane, the result of repeated measures ANOVA for changes of BUN, creatinine, and urine NAG-creatinine ratio shows no significant difference between the products with and without $\mathrm{KOH} \mathrm{(} \mathrm{P}=0.476,0.629,0.712$, Fig. 2).

\section{Discussion}

Carbon dioxide absorbent products can be classified into several groups: sodalime, Baralyme ${ }^{\circledR}$, and lithium hydroxide $(\mathrm{LiOH})$ based on their main chemical component. Sodalime, for 
Table 4. The Renal Safety Indicators at 24 Hours after Surgery in each Carbon Dioxide Absorbent Group

\begin{tabular}{clccc}
\hline Group & \multicolumn{1}{c}{ Indicator } & Sevoflurane & Isoflurane & P value \\
\hline \multirow{2}{*}{ A } & BUN (mg/dl) & $7.5 \pm 3.4$ & $8.5 \pm 3.3$ & 0.5804 \\
& Creatinine (mg/dl) & $0.60 \pm 0.07$ & $0.66 \pm 0.11$ & 0.2823 \\
& Urine NAG/Cr (IU/g Cr) & $6.4 \pm 5.5$ & $5.6 \pm 2.7$ & 0.6859 \\
B & BUN (mg/dl) & $9.4 \pm 3.5$ & $9.5 \pm 3.7$ & 0.9494 \\
& Creatinine (mg/dl) & $0.7 \pm 0.1$ & $0.7 \pm 0.1$ & 0.7801 \\
& Urine NAG/Cr (IU/g Cr) & $5.6 \pm 1.3$ & $7.6 \pm 4.8$ & 0.3497 \\
C & BUN (mg/dl) & $9.3 \pm 2.0$ & $8.1 \pm 2.3$ & 0.2836 \\
& Creatinine (mg/dl) & $0.6 \pm 0.1$ & $7.4 \pm 2.7$ & 0.3232 \\
D & Urine NAG/Cr (IU/g Cr) & $4.3 \pm 3.3$ & $7.9 \pm 2.8$ & 0.0437 \\
& BUN (mg/dl) & $10.3 \pm 3.5$ & $0.6 \pm 0.1$ & 0.1710 \\
& Creatinine (mg/dl) & $0.6 \pm 0.2$ & $5.2 \pm 3.0$ & 0.5661 \\
& Urine NAG/Cr (IU/g Cr) & $7.5 \pm 4.6$ & & 0.2700 \\
\hline
\end{tabular}

Table 5. The Changes of the Renal Safety Indicators at 72 Hours after Surgery Compared with Preoperative Value in each Carbon Dioxide Absorbent Group

\begin{tabular}{clccc}
\hline Group & \multicolumn{1}{c}{ Indicator } & Sevoflurane & Isoflurane & P value \\
\hline \multirow{2}{*}{ A } & BUN $(\mathrm{mg} / \mathrm{dl})$ & $-3.2 \pm 5.0$ & $-2.7 \pm 4.3$ & 0.8498 \\
& Creatinine $(\mathrm{mg} / \mathrm{dl})$ & $-0.12 \pm 0.13$ & $-0.13 \pm 0.10$ & 0.8672 \\
& Urine NAG/Cr (IU/g Cr) & $2.2 \pm 3.3$ & $0.4 \pm 3.0$ & 0.2642 \\
B & BUN (mg/dl) & $-1.9 \pm 3.0$ & $-1.7 \pm 2.7$ & 0.8960 \\
& Creatinine $(\mathrm{mg} / \mathrm{dl})$ & $-0.10 \pm 0.10$ & $-0.04 \pm 0.13$ & 0.3934 \\
& Urine NAG/Cr (IU/g Cr) & $-1.3 \pm 5.7$ & $-3.1 \pm 4.6$ & 0.1482 \\
C & BUN (mg/dl) & $-1.3 \pm 2.2$ & $-0.04 \pm 0.12$ & 0.1640 \\
& Creatinine $(\mathrm{mg} / \mathrm{dl})$ & $-0.10 \pm 0.12$ & $0.8 \pm 5.8$ & 0.3745 \\
& Urine NAG/Cr (IU/g Cr) & $-0.7 \pm 2.5$ & $-6.3 \pm 4.2$ & 0.4771 \\
$\mathrm{D}$ & BUN $(\mathrm{mg} / \mathrm{dl})$ & $-1.9 \pm 2.8$ & $-0.17 \pm 0.10$ & 0.0296 \\
& Creatinine $(\mathrm{mg} / \mathrm{dl})$ & $-0.11 \pm 0.10$ & $0.3 \pm 2.6$ & 0.2629 \\
& Urine NAG/Cr (IU/g Cr) & $2.0 \pm 3.0$ & 0.2563 \\
\hline
\end{tabular}
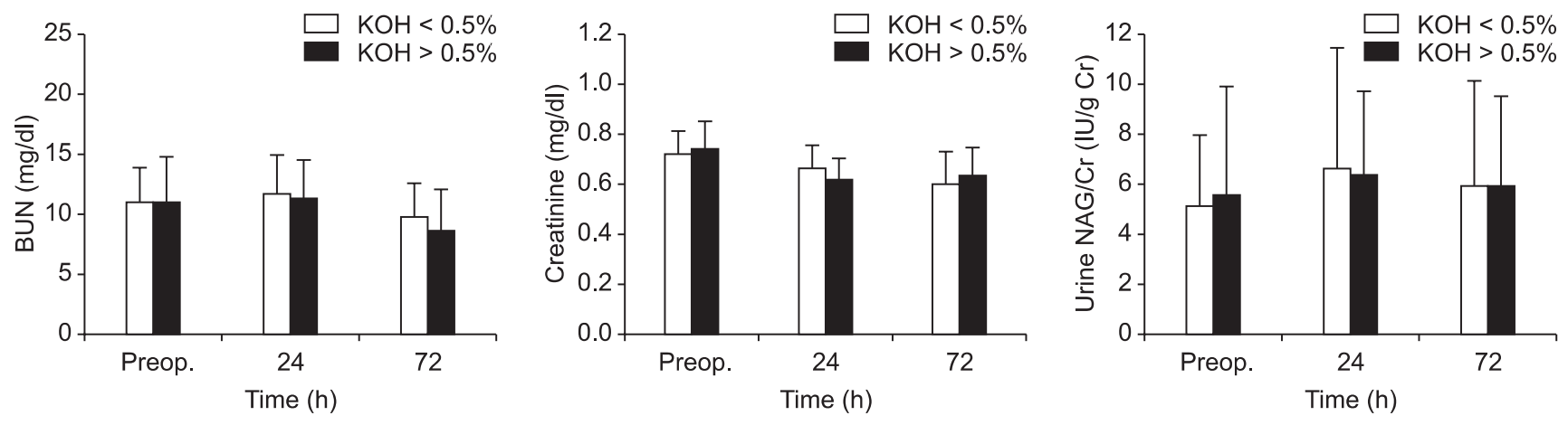

Fig. 2. Serum BUN, creatinine and urine NAG-creatinine ratios at preoperative, 24 hours and 72 hours after surgery in the group of carbon dioxide absorbents with and without $\mathrm{KOH}$. There was no significant difference between groups with respect to KOH. Preop.: Preoperative.

example is composed of calcium hydroxide $\left(\mathrm{Ca}[\mathrm{OH}]_{2}\right)$, sodium hydroxide $(\mathrm{NaOH})$, potassium hydroxide $(\mathrm{KOH})$, and water. These chemical compositions of carbon dioxide absorbents can also influence their reactions with sevoflurane, and the production of compound A [7].

Of these materials, the strong bases, such as $\mathrm{NaOH}$ and $\mathrm{KOH}$ are traditionally used to improve the efficiency of carbon dioxide removal. However, some research has reported that using these substances can produce larger amounts of compound A than the absorbent without these materials [12,14]. In addition to this, some authors have reported that the carbon dioxide absorbent products which does not contain these monovalent bases produce less compound A [15], although these differences were not shown in other studies $[7,11]$. Though controversial, carbon dioxide with $\mathrm{NaOH}$ or $\mathrm{KOH}$ are not used in the United States and Germany. However, products 
containing these strong bases are nonethelessly used in other countries (Table 1).

Among the carbon dioxide absorbents tested in this study, Sodasorblime ${ }^{\circledR}$ and Sodalyme ${ }^{\circledR}$, which contain $\mathrm{KOH}$, are made in Korea. While Sodasorb ${ }^{\circledR}$ and Spherasorb ${ }^{\circledR}$, which do not containing these materials, are the product of the United States and United Kingdom. However, the result of this study shows no significant difference between them (Fig. 2).

The water in carbon dioxide absorbent also affects the production of compound A. For example, in Baralyme ${ }^{\circledR}$, water decreases the concentration of compound A. However wet soda lime produce larger concentrations of compound A [16,17]. Once opened, the water contents in carbon dioxide absorbent could be changed. To eliminate these disturbances, we replaced all carbon dioxide absorbents with new absorbents before the induction of anesthesia.

In this study, the decrease of BUN at 72 hours after surgery was less prominent in patients with sevoflurane than with isoflurane in group D. The urine NAG-creatinine ratio at 72 hours after surgery was lower in patients using sevoflurane than in isoflurane in group C. A simple interpretation of this result suggests that differences exist between the sevoflurane and isoflurane subgroups in some carbon dioxide product groups. However, clinical implication of these results is ambiguous because patients exposed to sevoflurane show less renal injury markers than the control group.

According to the literature, exposure to compound A over $150 \mathrm{ppm} \cdot \mathrm{h}$ is known to cause dose dependent albuminuria, glucosuria, or enzymuria [5]. However, the exposure less than this level could not cause any detectable renal toxicity in human subjects. In this study, the use of sevoflurane was $2.36 \pm 0.89$ MAC $h$ with a fresh gas flow of $2 \mathrm{~L} / \mathrm{min}$, which can be converted to $14 \mathrm{ppm} / \mathrm{h}$ of compound A based on a previous study [18]. This might be insufficient to cause renal toxicity. However, it could be relevant to the purpose of this study if there are significant differences between the nephrotoxicity of carbon dioxide absorbent products.

For evaluating renal safety, this study checked serum BUN, creatinine concentration and urine NAG-creatinine ratios. In the previous human studies, only urine albumin, glucose, alpha-GST (glutathione-S-transferase) and pi-GST were reported to be increased after exposure to compound A $[19,20]$. In this study, serum BUN and creatinine were used, because not only are they the most widely used clinical markers of renal function, but also clinical significance of transient glucosuria, albuminuria, and enzymuria are uncertain [21]. Instead, urine NAG, a selective renal tubular injury marker [22], was used for differential diagnosis of other causes of renal injury because the renal tubule is the site damaged by compound $\mathrm{A}$ in an animal study [23].
In this study, sevoflurane was used with a fresh gas flow of $2 \mathrm{~L} / \mathrm{min}$. Our results are in accordance with another study evaluating liver and renal function after prolonged use of sevoflurane over 8 hours with a fresh gas flow of $5 \mathrm{~L} / \mathrm{min}$ and $0.5 \mathrm{~L} / \mathrm{min}$ [24]. In the study, BUN, creatinine, and uinalysis were checked, but all were within the normal range at 1,3, and 5 days after surgery. They used one carbon dioxide absorbent product (Spherasorb ${ }^{\circledR}$, Intersurgical, England) and the differences by carbon dioxide absorbents were not evaluated.

In this study, the renal safety between four carbon dioxide absorbent products in the patients under sevoflurane anesthesia was examined. As a result, some differences in renal safety markers were found but not to a clinically meaningful degree. However, carbon dioxide absorbent can produce materials that are inhaled into the human respiratory tract during sevoflurane anesthesia. From the result of this study, we recommend that the Food and Drug Administration in nations where it is not treated as a medical device should also consider treating it as a medical device and control it by the regulation on its efficacy and safety.

\section{Acknowledgments}

We really appreciate Eun-ju Seo for her administrative help and Min-jung Kim (CRC) and Moon-sun Woo (CRC) for their assistance in data collection. This study was supported by a grant from Seoul National University Hospital, 2009 (041120090046, Commissioned by Hana Pharm., Co., Ltd.).

\section{References}

1. Gonsowski CT, Laster MJ, Eger EI 2nd, Ferrell LD, Kerschmann RL. Toxicity of compound A in rats. Effect of increasing duration of administration. Anesthesiology 1994; 80: 566-73.

2. Obata R, Bito H, Ohmura M, Moriwaki G, Ikeuchi Y, Katoh T, et al. The effects of prolonged low-flow sevoflurane anesthesia on renal and hepatic function. Anesth Analg 2000; 91: 1262-8.

3. Kharasch ED, Frink EJ Jr, Artru A, Michalowski P, Rooke GA, Nogami W. Long-duration low-flow sevoflurane and isoflurane effects on postoperative renal and hepatic function. Anesth Analg 2001; 93: 1511-20.

4. Mazze RI, Jamison RL. Low-flow (1 1/min) sevoflurane: is it safe? Anesthesiology 1997; 86: 1225-7.

5. Bedford RF, Ives HE. The renal safety of sevoflurane. Anesth Analg 2000; 90: 505-8.

6. KFDA, 10 Jan, 2011. Search for item classification. Retrieved from http://md.kfda.go.kr.

7. Stabernack CR, Brown R, Laster MJ, Dudziak R, Eger EI 2nd. Absorbents differ enormously in their capacity to produce compound A and carbon monoxide. Anesth Analg 2000; 90: 1428-35.

8. Keijzer C, Perez RS, de Lange JJ. Compound A and carbon monoxide production from sevoflurane and seven different types 
of carbon dioxide absorbent in a patient model. Acta Anaesthesiol Scand 2007; 51: 31-7.

9. Kharasch ED, Powers KM, Artru AA. Comparison of Amsorb, sodalime, and Baralyme degradation of volatile anesthetics and formation of carbon monoxide and compound $\mathrm{A}$ in swine in vivo. Anesthesiology 2002; 96: 173-82.

10. Versichelen LF, Bouche MP, Rolly G, Van Bocxlaer JF, Struys MM, De Leenheer AP, et al. Only carbon dioxide absorbents free of both $\mathrm{NaOH}$ and $\mathrm{KOH}$ do not generate compound A during In vitro closed-system sevoflurane: evaluation of five absorbents. Anesthesiology 2001; 95: 750-5.

11. Versichelen L, Bouche MP, Struys M, Van Bocxlaer J, Mortier E, de Leenheer AP, et al. Compound A production from sevoflurane is not less when $\mathrm{KOH}$-free absorbent is used in a closed-circuit lung model system. Br J Anaesth 2001; 86: 345-8.

12. Yamakage M, Yamada S, Chen X, Iwasaki S, Tsujiguchi N, Namiki A. Carbon dioxide absorbents containing potassium hydroxide produce much larger concentrations of compound A from sevoflurane in clinical practice. Anesth Analg 2000; 91: 220-4.

13. Katoh T, Ikeda K. The minimum alveolar concentration (MAC) of sevoflurane in humans. Anesthesiology 1987; 66: 301-3.

14. Higuchi H, Adachi Y, Arimura S, Kanno M, Satoh T. Compound A concentrations during low-flow sevoflurane anesthesia correlate directly with the concentration of monovalent bases in carbon dioxide absorbents. Anesth Analg 2000; 91: 434-9.

15. Neumann MA, Laster MJ, Weiskopf RB, Gong DH, Dudziak R, Forster $\mathrm{H}$, et al. The elimination of sodium and potassium hydroxides from desiccated soda lime diminishes degradation of desflurane to carbon monoxide and sevoflurane to compound A but does not compromise carbon dioxide absorption. Anesth Analg 1999; 89: 768-73.
16. Steffey EP, Laster MJ, Ionescu P, Eger EI 2nd, Gong D, Weiskopf RB. Dehydration of baralyme increases compound A resulting from sevoflurane degradation in a standard anesthetic circuit used to anesthetize swine. Anesth Analg 1997; 85: 1382-6.

17. Eger EI 2nd, Ionescu P, Laster MJ, Weiskopf RB. Baralyme dehydration increases and soda lime dehydration decreases the concentration of compound A resulting from sevoflurane degradation in a standard anesthetic circuit. Anesth Analg 1997; 85: 892-8.

18. Bito H, Ikeda K. Effect of total flow rate on the concentration of degradation products generated by reaction between sevoflurane and soda lime. Br J Anaesth 1995; 74: 667-9.

19. Ebert TJ, Frink EJ Jr, Kharasch ED. Absence of biochemical evidence for renal and hepatic dysfunction after 8 hours of 1.25 minimum alveolar concentration sevoflurane anesthesia in volunteers. Anesthesiology 1998; 88: 601-10.

20. Eger EI 2nd, Gong D, Koblin DD, Bowland T, Ionescu P, Laster MJ, et al. Dose-related biochemical markers of renal injury after sevoflurane versus desflurane anesthesia in volunteers. Anesth Analg 1997; 85: 1154-63.

21. Baines AD. Strategies and criteria for developing new urinalysis tests. Kidney Int Suppl 1994; 47: S137-41.

22. Kind PR. N-Acetyl-beta-D-glucosaminidase in urine of patients with renal disease, and after renal transplants and surgery. Clin Chim Acta 1982; 119: 89-97.

23. Keller KA, Callan C, Prokocimer P, Delgado-Herrera L, Friedman MB, Hoffman GM, et al. Inhalation toxicity study of a haloalkene degradant of sevoflurane, Compound A (PIFE), in Sprague-Dawley rats. Anesthesiology 1995; 83: 1220-32.

24. Choi SR, Cho WJ, Chin YJ, Chung CJ. The effects of prolonged minimal-flow sevoflurane anesthesia on postoperative hepatic and renal function. Korean J Anesthesiol 2008; 54: 501-6. 